\title{
Soils apart from equilibrium - consequences for soil carbon balance modelling
}

\author{
T. Wutzler and M. Reichstein \\ Max Planck Institute for Biogeochemistry, Jena, Germany \\ Received: 28 August 2006 - Published in Biogeosciences Discuss.: 10 October 2006 \\ Revised: 6 February 2007 - Accepted: 7 February 2007 - Published: 15 February 2007
}

\begin{abstract}
Many projections of the soil carbon sink or source are based on kinetically defined carbon pool models. Parameters of these models are often determined in a way that the steady state of the model matches observed carbon stocks. The underlying simplifying assumption is that observed carbon stocks are near equilibrium. This assumption is challenged by observations of very old soils that do still accumulate carbon. In this modelling study we explored the consequences of the case where soils are apart from equilibrium. Calculation of equilibrium states of soils that are currently accumulating small amounts of carbon were performed using the Yasso model. It was found that already very small current accumulation rates cause big changes in theoretical equilibrium stocks, which can virtually approach infinity. We conclude that soils that have been disturbed several centuries ago are not in equilibrium but in a transient state because of the slowly ongoing accumulation of the slowest pool. A first consequence is that model calibrations to current carbon stocks that assume equilibrium state, overestimate the decay rate of the slowest pool. A second consequence is that spinup runs (simulations until equilibrium) overestimate stocks of recently disturbed sites. In order to account for these consequences, we propose a transient correction. This correction prescribes a lower decay rate of the slowest pool and accounts for disturbances in the past by decreasing the spinup-run predicted stocks to match an independent estimate of current soil carbon stocks. Application of this transient correction at a Central European beech forest site with a typical disturbance history resulted in an additional carbon fixation of $5.7 \pm 1.5 \mathrm{tC} / \mathrm{ha}$ within 100 years. Carbon storage capacity of disturbed forest soils is potentially much higher than currently assumed. Simulations that do not adequately account for the transient state of soil carbon stocks neglect a considerable amount of current carbon accumulation.
\end{abstract}

Correspondence to: T. Wutzler

(twutz@bgc-jena.mpg.de)

\section{Introduction}

The widely applied soil carbon models Century (e.g. Parton et al., 1988), Roth-C (Jenkinson, 1990), Romul (Chertov et al., 2001), Yasso (Liski et al., 2005) and many other models are based on kinetically defined pools. This means, that decomposition is described by removing a constant fraction of a pool at each time step. This fraction, which distinguishes the pools, is called the decay rate or decomposition rate. It is often modeled with a dependence on environmental conditions, in most cases temperature and moisture. Despite simplifying many soil processes, these models have proven to predict reasonable soil carbon stock changes during decadal time scales (e.g. Smith et al., 1997). However, there is a controversy whether the decay rates of the slower (more stable) pools have a lower, equal or higher dependence to warming than the faster pool (Ågren, 2000; Davidson and Janssens, 2006). The different answers to this question cause large differences in the long term soil carbon sink or source. While the decay rates of the faster pools have been determined by experimental results, the decay rates of the slower pools have been calibrated in a way that a models steady states matches observed carbon stocks (e.g. Liski et al., 2005). The underlying assumption is that the observed carbon stocks represent equilibrium stocks. This assumption also allows a determination of the initial state of the model for given constant average inputs and parameters by simulating the model until an equilibrium state is reached (spin-up-runs) (e.g. Smith et al., 2005). However, observed soils might be far away from equilibrium because of possible very long turnover times of stable compounds and disturbances by fire, erosion, land use or land use change. The equilibrium assumption is challenged by observations of steadily increasing carbon stocks of very old soils. Wardle et al. (1997) observed carbon stocks of about $240 \mathrm{tC} / \mathrm{ha}$ in the organic layer on small islands in northern Sweden, where fire was prevented. Sizes of the stocks correlate with the time since last disturbance (1000 to 3000 years).

Published by Copernicus GmbH on behalf of the European Geosciences Union. 


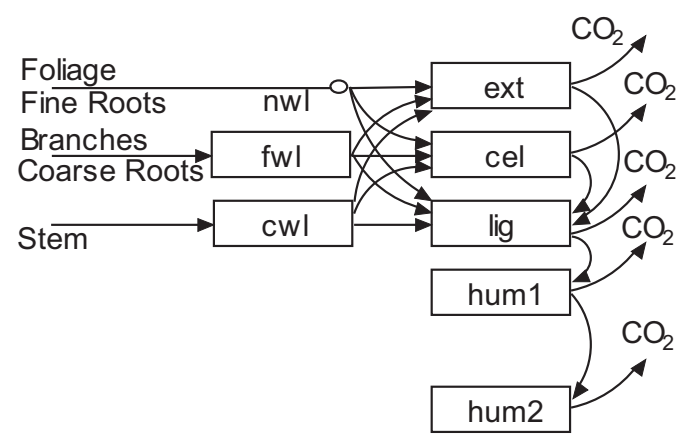

Fig. 1. Model Structure of the Yasso Model (Liski et al., 2005). The pools on the left side describe woody litter that becomes available for decomposition after a delay (nwl: non-woody litter, fwl: fine woody litter, cwl: coarse woody litter). The pools on the right side (ext: extractives, cel: celluloses, lig: lignin, hum1: humus1, hum2: humus2) represent soil carbon pools of different stability that are modeled by different decay rates of an exponential decay. The ext pool has the largest decay rate (i.e. least stability and shortest turnover time) and the hum 2 pool has the smallest decay rate (i.e. highest stability and longest turnover time).

This implies increasing stocks at old soils. Many modellers argue that the equilibrium assumption might be wrong, but it works and must be used until other approaches are evolving. Nevertheless, the consequences of relaxing the equilibrium assumptions are not well understood.

The aim of this study was to explore the consequences of a relaxed equilibrium assumption. The paper has the following outline. In a first part we perform an equilibrium experiment using the Yasso model's standard parameterization and show that the decay rate of the slowest pool and theoretical equilibrium stocks are highly uncertain. This implies that soil might be far apart from theoretical equilibrium yet. Based on these findings we propose a method how to initialize models to a transient state instead of equilibrium. In a second part we apply this initialization to a Central European case study. We discuss consequences for current soil modelling. Further, we show and discuss ways to overcome the equilibrium assumption.

\section{Methods}

\subsection{The Yasso model}

The soil carbon model Yasso was designed by Liski et al. (2005) in order to model soil carbon stocks of mineral soils in managed forests. Despite its simplicity and low demands on input data and parameters it shares many properties of the family of models that are based on kinetically defined pools. Figure 1 displays the model structure and the flow of carbon. The right part describes the separation of the different litter types into compartments that correspond to the kinetically defined pools and it describes a delay of

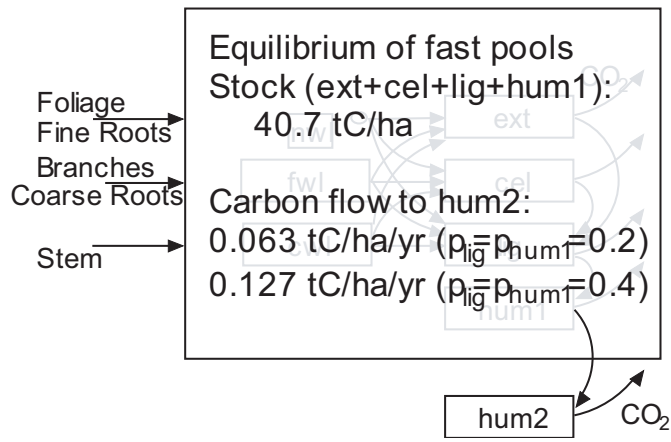

Fig. 2. Relaxed equilibrium assumption: All pools are assumed to be in equilibrium except the slowest pool (hum2). Constant average litter input determines equilibrium stocks of the faster pools and the constant flow to the slowest pool.

the woody litter compartments before decomposers can attack the chemical compounds. The left part describes the decomposition of the chemical compounds. The decay rates are dependent on mean annual temperature (or alternatively effective temperature sum) and a drought index (difference between precipitation and potential evapotranspiration during vegetation period). In the standard parameterization the decay rates of the slower pools are less sensitive to temperature increase than the fast pools (hums one: 60\%, humus two: $36 \%$ of sensitivity of fast pools). The model has been tested and successfully applied to boreal forest (Peltoniemi et al., 2004), litter bag studies in Canada (Palosuo et al., 2005), and as part of the CO2FIX model all over Europe (e.g. Kaipainen et al., 2004; e.g. Nabuurs and Schelhaas, 2002).

\subsection{The relaxed equilibrium assumption}

The relaxed equilibrium assumption corresponded to the usual equilibrium assumption, except that the slowest pool was excluded from this assumption. Assuming that time since last disturbance is longer than a century and that the inputs to the soil system did not change much within this time, the faster pools (turnover times of at most decadal time scale) have had enough time to recover from former disturbance. They were regarded to be near a dynamic equilibrium (averaging across changes during rotation periods and with climate fluctuations). The relaxed equilibrium assumption assumed that this is not true for the slowest pool which needs long time scales to reach the theoretical equilibrium. Hence the relaxed equilibrium assumption assumed the slowest pool to be still accumulating (Table 1). If all the faster pools are in equilibrium, the input rate to the slowest pool is constant (Fig. 2).

\subsection{The equilibrium experiment}

Using this relaxed equilibrium assumption we determined the decay rates of the slowest pool of soils that are recovering 
from former disturbance. The development of the carbon stock of the slowest pool $C$ (tC/ha) over time $t$ (yr) was described by a first order kinetics with decay rate $k(1 / \mathrm{yr})$ and with input $i$ (tC/ha/yr) (Eq. 1).

$\frac{\delta C}{\delta t}=i-k \cdot C$

When applying a constant input rate, integration of Eq. (1) resulted in the closed form of Eq. (2), where $a$ (dimensionless) is an integration constant.

$C=\frac{i}{k}\left(1-a e^{-k \cdot t}\right)$

Constraining the stock at time $t=0$ to $C_{0}$ in Eq. (2) gives Eq. (3).

$C=\frac{i}{k}-\left(\frac{i}{k}-C_{0}\right) \cdot e^{-k \cdot t}$

The decay rate $k$ can be expressed as a function of the current stock $C_{c}$, (tC/ha), input $i$, and by an approximation of its current rate of assimilation $\frac{\Delta C_{c}}{\Delta t}(\mathrm{tC} / \mathrm{ha} / \mathrm{yr})$. Resolving Eq. (1) for the decay rate gives Eq. (4).

$k=\frac{i-\frac{\Delta C_{c}}{\Delta t}}{C_{c}}$

For a given decay rate $k$, the equilibrium stock, which corresponds to an assimilation rate of 0 , is given by Eq. (5).

$C_{e}=\frac{i}{k}$

And the accumulation time $t_{95}(\mathrm{yr})$, i.e. the time for an increase of stocks from zero to $95 \%$ of equilibrium stock, is given by Eq. (6).

$t_{95}=\frac{\ln \left(0.05 \cdot C_{e}\right)}{k}$

In the equilibrium experiment we prescribed different current assimilation rates and calculated corresponding decay rates of the slowest pool (Eq. 4). Given these decay rates, we determined equilibrium stocks (Eq. 5), and the times that are needed to accumulate $95 \%$ of these stocks (Eq. 6). Initial pools size $(40.7 \mathrm{t} / \mathrm{ha})$ and input to the slowest pool $(\mathrm{i}=0.063 \mathrm{tC} / \mathrm{ha} / \mathrm{yr}$ ) were calculated by equilibrium of the faster pools of the Yasso model with standard parameterization for Norway spruce in standard climate (Appendix B). Reasonable constant average litter inputs of Norway spruce were applied (non woody litter=1.7 tC/ha/yr, fine woody litter $=1.4 \mathrm{tC} / \mathrm{ha} / \mathrm{yr}$, thin coarse woody litter $=0.1 \mathrm{tC} / \mathrm{ha} / \mathrm{yr}$, large coarse woody litter $=0.1 \mathrm{tC} / \mathrm{ha} / \mathrm{yr}$ ). The development of carbon stocks with average litter inputs represents the trend (moving average over time) of the carbon stocks that result from the application of non-constant litter input. Additionally, calculations were repeated using an increased input to the slow pool $(i=0.127 \mathrm{tC} / \mathrm{ha} / \mathrm{yr})$ that resulted from a change in the Yasso parameterization in which a larger part of decay material was spent to form more recalcitrant compounds $\left(p_{\text {lig }}=p_{\text {hum } 1}=0.4\right)$.
Table 1. Comparison of equations between the usual equilibrium assumption and the relaxed equilibrium assumption for the slowest pool. $k$ : decay rate, $i$ : input rate, $C_{c}$ : current stock, $C_{e}$ : equilibrium stock.

\begin{tabular}{lll}
\hline & Usual & Relaxed \\
\hline Equilibrium stock & $C_{e}=\frac{i}{k}=C_{C}$ & $C_{e}=\frac{i}{k}>C_{C}$ \\
Mass balance & $i=k \cdot C_{c} ; \quad \frac{\delta C_{c}}{\delta t}=0$ & $i=k \cdot C_{c}+\frac{\delta C_{c}}{\delta t}$ \\
Decay rate & $k=\frac{i}{C_{c}}$ & $k=\frac{i-\frac{\delta C_{c}}{\delta t}}{C_{c}}$ \\
\hline
\end{tabular}

\subsection{The transient correction}

In continuation to the results of the equilibrium experiment, we developed a method of correcting spin-up-run predicted pool sizes for the effects of former disturbance. This "transient correction" is only valid for sites that have not been disturbed for about a century, because it uses the relaxed equilibrium assumption, which assumes that all pools are in equilibrium except the slowest pool. According to the results of the equilibrium experiment, which are described in the results section of this study, the effects of former disturbance are an overestimation of the slowest pool's decay rate in model calibration and that current carbon stocks are smaller than equilibrium carbon stocks. Hence, the correction, first, prescribes a lower decay rate of the slowest pool. Below it will be shown that about $20 \%$ of the decay rate that is determined by the usual equilibrium assumption is appropriate for century term simulations. Second, the correction decreases the spin-up-run predicted equilibrium stock of the slowest pool by subtracting an amount of carbon. The amount that has to be subtracted is chosen so that the sum of the stocks of the soil carbon pools matches an independent estimate of current carbon stocks.

\subsection{Application of the transient correction}

In order to test the performance of the transient correction, we applied the transient correction at a Central European beech forest chronosequence (Mühlhausen/Leinefelde). The sites of the chronosequence have been managed as a shelterwood system. In the EU-project FORCAST, litter fall, organic layer carbon stocks, and soil carbon stocks have been measured (Mund, 2004). Carbon pools of the soil model were initialized with spin up runs with constant average litter inputs and climatic conditions (mean average temperature: $6.8^{\circ} \mathrm{C}$, drought index: $71.3 \mathrm{~mm}$ ). All sites of the chronosequence have been disturbed by wood pasture about 150 years ago and some sites have been possibly used as agricultural land before the 16th century. The several sites of the chronosequence represent different stand ages of the one simulated site. As independent estimate of soil carbon stocks for the transient correction the sum of the measured 
Table 2. Scenario groups of the simulations of the Leinefelde/Mühlhausen chronosequence. Within each group simulations were performed with different decay rates of the slowest pool (hum2) and repeated with increased temperature sensitivity.

\begin{tabular}{ll}
\hline Scenario group & Description \\
\hline base & $\begin{array}{l}\text { current inputs and current temperature } \\
\text { increase of litter inputs by assuming that all } \\
\text { the wood remains in the forest (conserva- } \\
\text { tion scenario) } \\
\text { increase of temperature by 3,6, and 9 Kelvin } \\
\text { gradually over the next 100 years } \\
\text { increase of litter input and increase of tem- } \\
\text { perature by } 3 \text { Kelvin }\end{array}$ \\
t3+litter &
\end{tabular}

Table 3. Average litter inputs to the Yasso model [tC/ha/yr]. nwl: non woody litter, fwl: fine woody litter, cwl_small: coarse woody litter with a diameter diameter $6-20 \mathrm{~cm}$, cwl_large: coarse woody litter with a diameter $20-60 \mathrm{~cm}$.

\begin{tabular}{lllll}
\hline Scenario group & nwl & fwl & cwl_small & cwl_large \\
\hline base, t3-t9 & 3.148693 & 0.528087 & 0.208115 & 0.08467 \\
litter, t3+litter & 3.148693 & 0.865541 & 1.242068 & 0.213914 \\
\hline
\end{tabular}

carbon stocks of the mineral soil $(41.7 \pm 5.0 \mathrm{tC} / \mathrm{ha})$ and the organic layer $(3.7 \pm 0.8 \mathrm{tC} / \mathrm{ha})$ was used. The used standard parameterization of the Yasso model is listed in Appendix B.

We studied the effect of assuming different intrinsic decay rate of the hum 2 pool (slowest most stable pool of the Yasso model) on both, the average carbon stock, and the uncertainty of the carbon stocks after 100 years. The decay rate was varied by dividing the standard value of $1.2 \mathrm{e}-3 \mathrm{yr}^{-1}$ by $1,5,25,125$, and 625 . This corresponds to turnover times of 830 to $5.2 \mathrm{e} 5$ years. We used four scenario groups in order to gain insight, in how this effect varies with combinations of changes in temperature and litter input (Table 2). Table 3 lists average litter inputs to the Yasso model. We did not vary litter inputs with stand age but applied a constant litter input that was averaged across one rotation cycle. For details of derivation of litter input see Appendix A. First we studied the effect with four scenario groups and standard parameterization. Next, we studied the effect in four scenario groups that differed from the corresponding previous scenario groups by increased temperature sensitivity of the slow pools apparent decay rate. The apparent decay rate depends on the intrinsic decay rate, water availability, temperature, and several parameters. We modified the standard parameterization in a way so that the slowest pools were as sensitive to warming as the decay rates of fast pools $(s 1=s 2=100 \%)$.

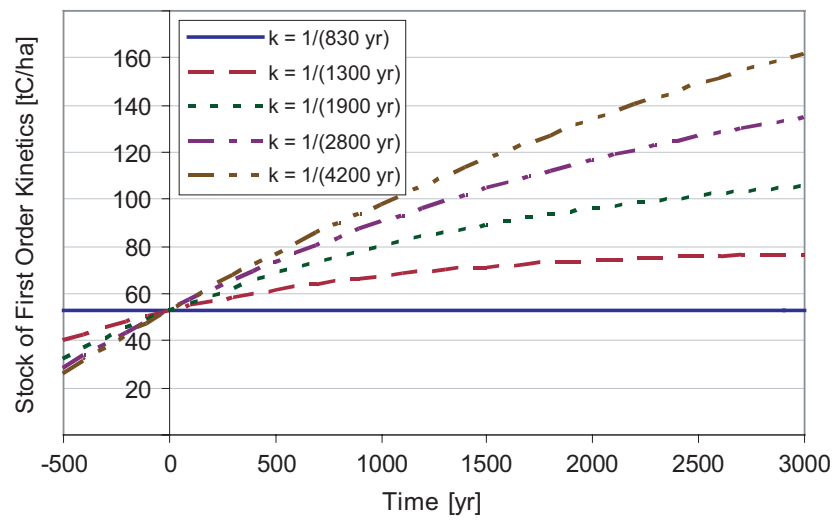

Fig. 3. Trajectories of the slowest pool of the Yasso model with different decay rates. Dynamics is described by a first order kinetics with constant input (Eq. 3): $C=\frac{i}{k}-\left(\frac{i}{k}-C_{0}\right) \cdot e^{-k \cdot t}$; input $i=0.06345 \mathrm{tC} / \mathrm{ha} / \mathrm{yr}$; stock at time zero $C_{0}=52.874 \mathrm{tC} / \mathrm{ha}$. At time $t=0$ the current carbon stock $C_{0}$ is observed. The lower the decay rate, the larger is the current rate of carbon accumulation, which is given by the slope $\Delta \mathrm{C} / \Delta \mathrm{t}$ at time zero.

\section{Results}

3.1 Decay rates and equilibrium stocks in the equilibrium experiment

Current carbon stocks can be explained by different decay rates of the slowest pool if the equilibrium stock is not fixed (Fig. 3). The difference between the trajectories of carbon stocks with different decay rates within a few years is very small $(<10 \mathrm{~g} / \mathrm{ha} / \mathrm{yr})$. However, the assumption of already very small current accumulation rates in the equilibrium experiment resulted in profound changes of equilibrium stocks. We calculated (Eqs. 4-6) large changes in the resulting decay rate (Fig. 4a), in the theoretical equilibrium stocks (Fig. 4b) and the accumulation times (Fig. 4c). This is explained as follows. If the assumed rate of change was approaching the input rate to the slowest pool, the difference between input and accumulation approached zero. Hence, the decay rate also approached zero (Fig. 4a). This caused the equilibrium stocks and the times to reach these stocks to approach infinity. The limit case, when the rate of change was equal to the input, corresponded to an inert pool that is not decomposed. With doubling the proportion of carbon that is used to form more recalcitrant components $p_{\text {lig }}=p_{\text {hum } 1}=0.4$, the limit case had a different position. However, despite this big change to the model, the pattern was the same. With the assumption of small current accumulation rates decomposition rates were much lower (Fig. 4a cross symbols) than without a current carbon accumulation and theoretical equilibrium stocks were much higher (Fig. $4 \mathrm{c}$ cross symbols). 

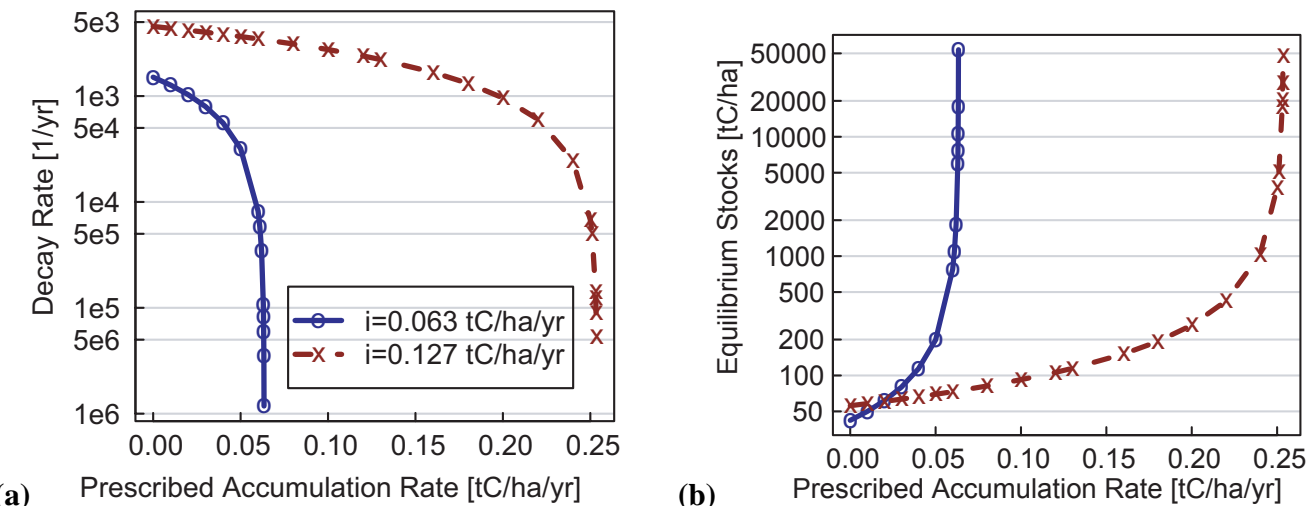

(a)

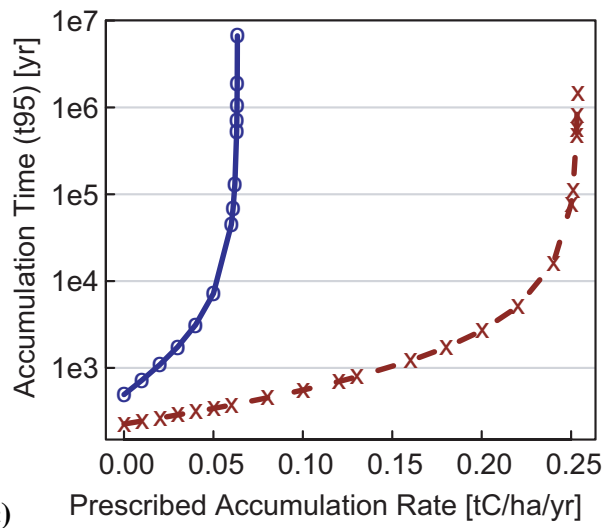

Fig. 4. Decay rates (a) (Eq. 4), equilibrium stocks (b) (Eq. 5), and accumulation times (c) (Eq. 6) that result when different rates of current carbon accumulation (x-axis) are prescribed. Symbols correspond to two different equilibrium inputs that result from a variation in the proportion of decomposed mass in the Yasso Model.

3.2 Effects of accounting for former disturbance by the application of the transient correction

The sum of the equilibrium carbon pools after the spinup-run exceeded observed stocks by about $30 \%$ for the Mühlhausen/Leinefelde study site that has been disturbed until 150 years ago (Fig. 5). With the relaxed equilibrium assumption (all pools are in equilibrium except the slowest pool), we interpreted that the slowest pool (hum2) was far from equilibrium yet. The application of the transient correction decreased the slowest pool, i.e. the carbon above the line of observed carbon stocks in Fig. 5. In the scenario of increased temperature sensitivity the relative proportion of the slowest pool after the correction was larger because the spinup-runs resulted in smaller sum of stocks of all the pools.

The carbon accumulation due to the adjustment of the spin-up-run predicted pools for former disturbances was $5.7 \pm 1.5 \mathrm{tC} / \mathrm{ha}$ with standard temperature sensitivity (Fig. 6 top left) and $5.5 \pm 1.8 \mathrm{tC} / \mathrm{ha}$ with increased temperature sensitivity (Fig. 7 top left) within 100 years for the baseline scenario. This corresponds to a flux of $5.7 \mathrm{gC} / \mathrm{m}^{2} / \mathrm{yr}$ and an increase of about $13 \%$ of initial carbon stocks over 100 years.
This carbon accumulation would have been neglected without the transient correction. The transient correction prescribes a lower intrinsic decay rate of the slowest pool but does not specify this rate. Hence, we studied the uncertainty that resulted from a range of prescribed decay rates that correspond to turnover times from 830 to $5.2 \mathrm{e} 5$ years. The absolute amount of uncertainty of $1.5 \mathrm{tC} / \mathrm{ha}$ (or $1.8 \mathrm{tC} / \mathrm{ha}$ for increased slow pool temperature sensitivity) did not change much with different scenarios of litter input and temperature increase (Figs. 6 and 7). Hence the relative size of the uncertainty depended on the projected change of carbon stocks and varied between 9\% in the conservation scenario (Fig. 7 litter) and 59\% in the temperature increase scenario (Fig. 7 t3).

Assuming lower decay rates of the slowest pool resulted in an increased carbon accumulation (Fig. 8). Consistently across all scenario groups, the carbon accumulation increased most with the first decrease of the slowest pool's (hum2) decay rate to $20 \%$ of standard parameterization. Further decrease of the decay rate to $4 \%, 0.8 \%$, and $0.16 \%$ of standard parameterization only slightly increased carbon accumulation during 100 years. 


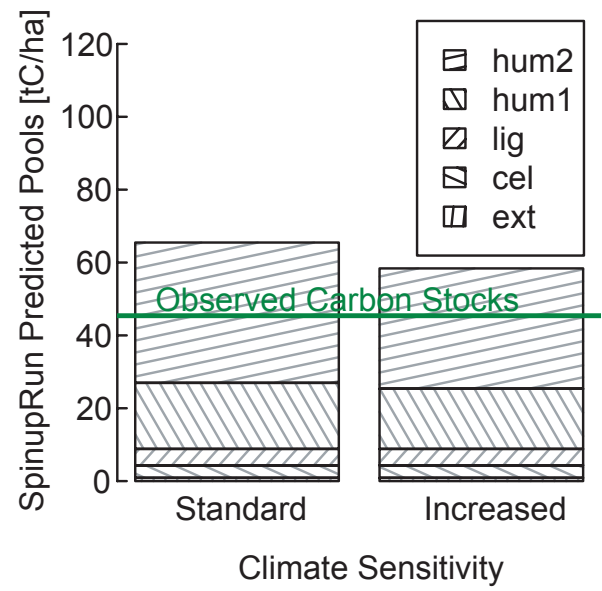

Fig. 5. Transient correction at the Mühlhausen/Leinefelde site. Spin-up-runs of the Yasso model simulate the theoretical equilibrium stocks of the kinetically defined soil carbon pools (ext, cel, lig, hum1, and hum2). The transient correction decreased the slowest pool (hum2) so that the sum of the pools matches the observed carbon stocks. Climatic sensitivity: The decay rates of the slower pools were less sensitive to warming than the faster pools with standard parameterization and equally sensitive $(s 1=s 2=100 \%)$ in the scenarios of increased temperature sensitivity.

\section{Discussion}

4.1 Highly uncertain decay rates and equilibrium stocks

Our study for the first times explores the consequences of relaxing the usual assumption that soil carbons stocks are in equilibrium. The consequences for the parameterization of slow pool decay rates and resulting theoretical long-term equilibrium were studied by performing an equilibrium experiment, in which the slowest pool was still accumulating carbon. The equilibrium experiment showed that already very small rates of current accumulation caused tremendous changes in equilibrium stocks (Fig. 4). The necessary accumulation rates are so small, that it is practically impossible to measure them within a few years. The times to reach equilibrium could span millennia. Hence, soils may be far apart from a theoretical equilibrium. The theoretical equilibrium does not account for non-respiratory losses out of the system. Hence, soils may never reach this theoretical equilibrium because of changing conditions and partial resets by disturbances (e.g. forest fires (Parker et al., 2001; Wardle et al., 2003), or erosion (Hedges et al., 1997; Polyakov and Lal, 2004)). In addition soil weathering continues and soil horizons may change in a way to increase humus stabilization and potential carbon stocks.
4.2 The transient correction - an approach to account for former disturbance

In order to account for former disturbances, we suggested a heuristic technique that we call the transient correction. Soils that have been disturbed centuries ago are still in a transient state due to the long timescales of the slowest pool. The transient correction can account for this transient state, where the relaxed equilibrium assumption is valid (time since last disturbance is longer than a century).

The transient correction does not specify the decay rate of the slowest pool, because the rate can not be determined by calibrating equilibrium states to current stocks or observing current stock changes. If no method of constraining this rate is available, 1/5 of the standard decay is a reasonable first estimate, because lower rates did not change results much in decadal time scale, as we showed in our sensitivity analysis (Fig. 8).

The transient correction modifies a valid state by changing the stock of a single pool. This procedure potentially may initialize models to non-valid states. However, most models have no feedbacks or very weak feedbacks from the slowest pool to the other pools. Hence, we do not expect big numerical errors or anomalies due to the transient correction when simulating the system.

One precondition for applying the transient correction is an independent estimate of current soil carbon stocks. This estimate must account for the disturbance history. Best choice is measuring carbon stocks at the site. However, this is laborious and expensive. If the disturbance history can be assumed to be similar within a region, a spatial extrapolation of measured carbon stocks can be used (e.g. Liski and Westman, 1997; Perruchoud et al., 2000; Wirth et al., 2004; Wutzler et al., 2006).

We note, that neither the equilibrium nor the relaxed equilibrium assumption is applicable for sites with more recent (less than a century ago) disturbances. In order to initialize the model for such sites, the stocks of all the pools have to be estimated. There are recent advances in reflectance methods to achieve this (Couteaux et al., 2003). Zimmermann et al. (2007) related fractions of grassland soil carbon that were chemically distinguished to the carbon pools used in the Roth-C model. These pools then could be classified quite well by analysing reflectance spectra.

\subsection{Incorrect initial model state and underestimation of car- bon accumulation and it's uncertainty}

Previous model studies of soil carbon stock changes (e.g. Liski et al., 2002) did not take detailed account for the effect of soils recovering from former disturbance. We exemplified the consequences of relaxing the equilibrium assumption on development of soil carbon by applying the transient correction together with the YASSO model to a Central European beech forest. 


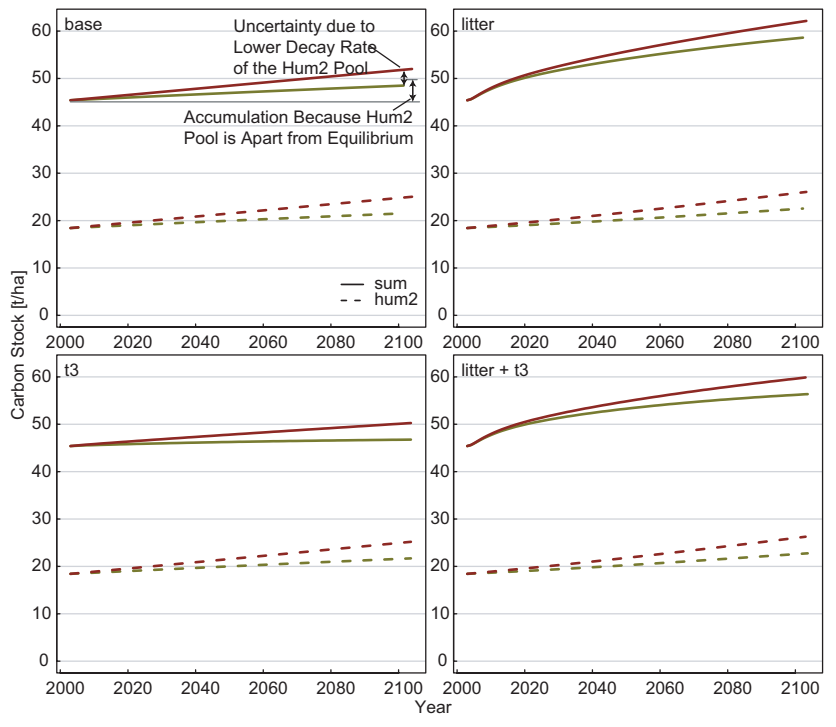

Fig. 6. Development of the soil carbon stocks at the Leinefelde chronosequence simulated by the Yasso model with standard temperature sensitivity. sum represent the sum of the stocks of the Yasso soil pools (ext+cel+lig+hum1+hum2). The lower ones of the diverging lines are trajectories of the simulation with standard parameterization of the slowest pool decay $\left(k_{\text {hum } 2}=1.20 \mathrm{e}-3\right)$ and upper ones of a much lower value $\left(k_{\text {hum } 2}=1.92 \mathrm{e}-06\right)$. The four panels correspond to different scenario groups (base: no change in litter inputs and temperature, litter: increase litter input, $\mathrm{t} 3$ : temperature increase of $3 \mathrm{~K}$ gradually over 100 years).

If soils are apart from equilibrium, this leads to a big overestimation of the decay rate of the slowest pool with the current method of constraining the slow pool decay rates. The spin-up-runs will still give reasonable results for soils that have a similar disturbance history as the sites used for parameterization of the model (Peltoniemi et al., 2004). However, with an overestimated decay rate of the slowest pool, the spin-up-runs underestimate the stock at sites that have not been disturbed for a very long time. Further, the spin-up-runs overestimate the stock at sites that have been disturbed in the last two or three centuries ago. For this time we can assume that the sites used for parameterization of the Yasso model have not been severely disturbed. The spinup-runs possibly will overestimate stock at sites where last disturbance is even longer ago, but this depends on disturbance history of the sites used for parameterization of the Yasso model.

When applying the transient correction to the Central European beech forest we found an additional increase of $5.7 \mathrm{~g} / \mathrm{m}^{2} / \mathrm{yr}$ due to recovering from disturbance (Fig. 6). This additional increase was of the same magnitude as the increase due to climate change projected for Finland $\left(9 \mathrm{~g} / \mathrm{m}^{2} / \mathrm{yr}\right)$ (Liski et al., 2006) or Sweden $\left(7.5 \mathrm{~g} / \mathrm{m}^{2} / \mathrm{yr}\right)$ (Ågren et al., 2007). In a first very rough extrapolation to European scale we assume that half of the forested area in Europe is still recovering from former disturbance and that the

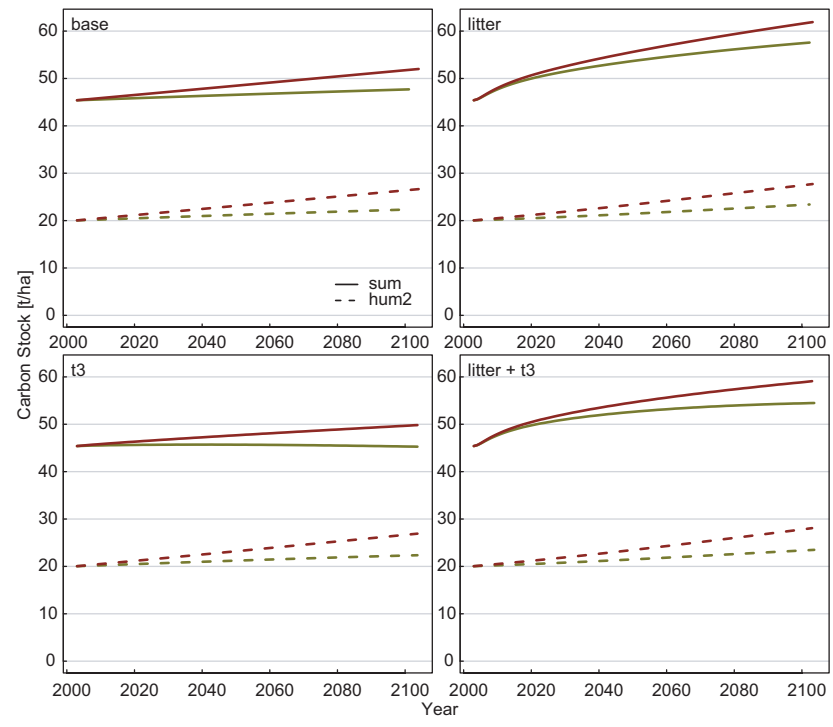

Fig. 7. Development of the soil carbon stocks at the Leinefelde chronosequence simulated like the ones in Fig. 6 except an increased temperature sensitivity of the slow pools $(s 1=s 2=100 \%)$.

additional increase that we calculated for the Leinefelde site would occur on this area. With these assumptions, the projected forest soil carbon sink of 7.5 TgC for Europe (EU15 + Norway + Switzerland: 120 million ha) by a recent LPJ modelling study by ATEAM (Lindner et al., 2004; Schröter et al., 2004 ) would be increased by $3.42 \mathrm{TgC}$ or by $46 \%$. Hence, the potential carbons sink due to recovering from former disturbance is in the same magnitude as the currently projected sink in Europe.

Relaxing the equilibrium assumption added another degree of uncertainty to projections of carbon stocks. With applying the transient correction, this additional uncertainty entered the model by the unknown slowest pools decay rate. The uncertainty of projected carbon stocks was smaller than projected stock change but of the same magnitude (Figs. 6 and 7). Further, the uncertainty varied with assumptions about the temperature sensitivity of the slow pools decay rates (Fig. 8). This variation of the uncertainty of carbon stock changes was caused in part by the higher initial percentage of the slow pool in the increased temperature sensitivity scenarios (Fig. 5). We suppose that uncertainty of stock changes due to slow pool parameterization will be largest in soils, where the initial percentage of the slow pool after the transient correction is large or where decay rates are high.

\subsection{Consequences apply also to other models}

The models Century (e.g. Parton et al., 1988), Coup (Jansson and Karlberg, 2004), Romul (Chertov et al., 2001), RothC (Jenkinson, 1990), and the soil model of Biome-BGC (Thornton, 1998) all define a very slow pool. Except Romul, which provides a database of compiled initial states, all 


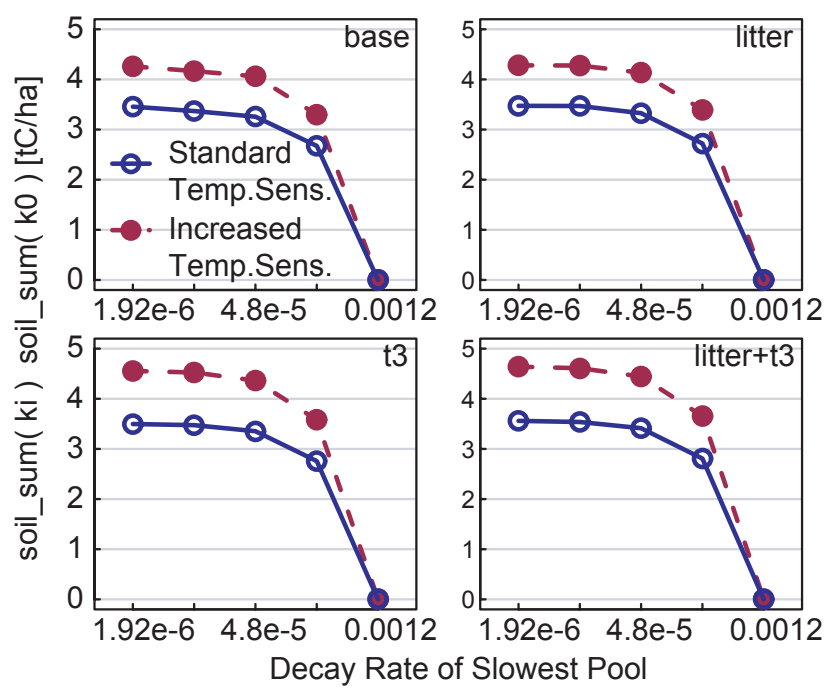

Fig. 8. Difference of carbon stocks from base line (standard parameterization, $k_{\text {hum } 2}=0.0012$ ) after 100 years (y-axis) caused by different parameterization of the decay rate of the slowest pool (logarithmic $\mathrm{x}$-axis). The four panels correspond to different scenario groups (base: no change, litter: increase litter input, t3: increased temperature).

these models use the equilibrium assumption to infer initial states. Therefore, the consequences of Yasso model simulations also apply to these models. The transient correction should also be readily applicable to these models except the RothC model. The RothC shares the same problem; however the application of the transient correction is impaired. This is because the model specifies no input to the inert pool and already calibrates the size of the inert pool in a way to match average age of soil carbon that was determined by $\mathrm{C} 14$ measurements (Falloon et al., 1998; Martel and Paul, 1974; Rumpel et al., 2002).

4.5 Evidence and tests for the hypothesis of soil carbon stock being apart from equilibrium

From repeated measurement after 5-10 years, we can practically not infer if a soil carbon stock is near equilibrium because small changes in carbon stocks could be attributed to inter-annual variance (Fig. 3). However, the influence of former disturbances, namely former land use, on current soil carbon stocks, C:N ratios, nitrification and other soil properties is confirmed by many studies at several sites (e.g. Berger et al., 2002; Goodale and Aber, 2001; Koerner et al., 1997; Mund, 2004; Mund and Schulze, 2005; Rothe et al., 2002; Thornton et al., 2002; Wardle et al., 1997). These influences can be much stronger than climatic influences (Caspersen et al., 2000; Janssens et al., 2001) and can be observed after 1700 years (Dupouey et al., 2002). A recent review regarding soil carbon changes in forests concludes that the vast intensive cultivation throughout Europe (deforestation, drainage, deflation and erosion) has caused immense historical losses of soil carbon. Nowadays forested areas with degraded soils are abundant and offer a tremendous potential to restore carbon stocks (Baritz et al., 2004). Foster et al. (2003) describe processes that alter soil properties in historic timescales. The most important ones are probably tillage (Grandy and Robertson, 2006; Wall and Hytonen, 2005) and erosion (Polyakov and Lal, 2004). Hence, we support the hypothesis that soil carbon stocks of many sites are apart from equilibrium. In order to further increase the evidence we suggest testing some consequences of the hypothesis.

One consequence is the underestimation of current soil carbon stocks for sites that have not been disturbed for a much longer time than the sites used for parameterization. Are these overestimations observed? We did not apply the Yasso model to the old-growth forest with high carbon stocks (Harmon et al., 2004; Wardle et al., 1997), but we realize that the litter input and adjustment of decay rates with climate would not be sufficient to simulate the large observed stocks. Soils with an even longer track (i.e. more than millennia) of stable conditions can be found at sites of tropical evergreen rainforests. However, caution has to be applied in translating models and parameters between boreal and temperate zone. Due to the very different apparent decay rates, the soil carbon stocks are not readily comparable between the temperate and the boreal zone.

A second consequence is the overestimation of current soil carbon stocks for sites that have been disturbed in the last two or three centuries ago. In this study we presented simulations of forest soils that have been disturbed by wood pasture 150 years ago with lower observed carbon stocks than stocks predicted by spin-up runs (Fig. 5). These observations confirm the notion of soils being apart from equilibrium.

Koerner et al. (1999) found that $\delta^{15} \mathrm{~N}$ values increase with intensity of former land use. They related this to former input of ${ }^{15} \mathrm{~N}$ enriched manure, and to the activation of soil nitrification. The increase $\delta^{15} \mathrm{~N}$ can be used as a (yet nonquantitative) tracer of previous land use in forests.

4.6 How can we interpret and constrain the slow pool's decay rate without assuming equilibrium?

Currently quite contrasting concepts are existing about which factors and processes determine the slow kinetically defined pools and their decay rate, where the biochemical properties of the decaying material (Berg and McClaugherty, 2003; Couteaux et al., 1995), physico-chemical stabilization (Mikutta et al., 2006; von Lützow et al., 2006) and microbial limitations of energy and nutrients (Fontaine and Barot, 2005) are mentioned as limiting factors. Couteaux et al. (1995) present a conceptual model of decomposition in the organic layer that is divided in three phases. The initial phase could be roughly attributed to the decay of the extractives, celluloses, and lignin pools of the Yasso model, the 
late phase to the pools lignin and humus one pool, and the final stage to the decay of the most recalcitrant pool. Howard et al. (1974) found, when extrapolating mass loss of litter bag studies with an asymptotic model, that in many cases the proportion of mass that is decayed, is smaller than $100 \%$ and that there is a part of the litter that is transformed to stable components. Berg et al. $(2003,1996)$ termed the asymptote of the decay "limit value" and showed that it can be correlated with litter quality and climatic conditions. If pools are attributed to the decay phases as described above, the portion above the limit value, i.e. the not or extremely slowly decomposing fraction, corresponds to the flux into the slowest pool. It needs to be investigated, if this approach together with the age of soil carbon (Falloon et al., 1998; Martel and Paul, 1974; Rumpel et al., 2002) can be used to constrain the slower pools without the equilibrium assumption. The parameterization of the slow pools then will depend on litter quality, namely initial nitrogen content, and climatic drivers.

Decomposition, especially the late states, also depends on soil mineralogy and spatial inaccessibility of carbon (Mikutta et al., 2006; von Lützow et al., 2006). Finally, Fontaine and Barot (2005) could increase dramatically the decay rates of the soil organic matter by increasing the energy input into the soil, indicating that microbial starvation could also be a reason for stabilization, particularly in deeper horizons. The YASSO model, however, assumes that decomposition is governed by chemical litter quality and climatic drivers. Hence, the transient correction should only be considered as a diagnostic approach and we believe that models need to be developed which explicitly represent these additional processes. These models will give better mechanistic constraints on and interpretation of soil organic matter decomposition rates.

\section{Conclusions}

- Observations of current soil carbon stocks are not sufficient to constrain the decay rates of the recalcitrant components and the corresponding equilibrium carbon stocks. The reason is that because of the long time scales of recovering from disturbances it is not known whether carbon stocks are in equilibrium.

- If soils are apart from equilibrium, spin-up runs are only valid for sites that have a similar disturbance history as the sites used for model calibration. The spin-up runs underestimate the stock of sites that have not been disturbed for a very long time, i.e. thousands of year, and overestimate the stock of sites that have been disturbed in the last two or three centuries

- Carbon stocks that have been generated by spin-up runs of models that work similar as YASSO should be corrected by the "transient correction". This means to adjust the slowest pool in a way that the sum of soil pools matches an independent estimate of soil carbon stocks.
Such an estimate can be obtained by soil carbon stock observations or by regional statistical models that can account for the unknown but similar disturbance history.

- In century-term simulations the uncertainty due to the unknown decay rate of the slowest pool results in uncertainty of stock changes in the magnitude of $1^{\prime} \mathrm{g} / \mathrm{m}^{2} / \mathrm{yr}$. This considerable amount of uncertainty is of the same magnitude of the simulated changes in soil carbon stocks due to litter input and climate change. The amount of uncertainty does not change very much with changing litter input and changing temperature. However, this amount increases with temperature sensitivity of the slow pools and the initial proportion of the stock of the slowest carbon pool.

- Carbon storage capacity of disturbed forest soils is potentially much higher than currently assumed.

- Century-term simulation of changes in soil carbon stocks that use spin-up-runs without the transient correction miss a considerable amount of carbon accumulation at many disturbed forest sites.

\section{Appendix A}

\section{Calculation of average litter inputs}

In addition to the measured litter input, we calculated input by harvest residues and coarse roots after harvest in the following way. Merchantable timber volume and volume increment of the remaining part of the stand was estimated by yield tables (Dittmar et al., 1986). We assumed a harvest of $50 \%$ of the volume at age 140 years and $15 \%, 15 \%$ and $20 \%$ at the ages 150,160, 170 years, respectively. Carbon mass of tree compartments stem, branches were estimated by age and site index dependent conversion factors of Wirth et al. (2004). Extracted wood volume on harvest was $92 \%$ of merchantable timber volume (G. Weber, personal communication). Carbon mass of harvest residues was calculated by the difference between stem/branch carbon and the carbon mass of the extracted wood by applying a wood density of $0.56 \mathrm{t} / \mathrm{m}^{3}$ and a carbon concentration of $48.6 \%$ (Weiss et al., 2000). The harvest residues and roots were partitioned to the inputs of the Yasso model according to Table A1. The coarse woody part of harvest residues was removed by about $90 \%$ by wood pickers (M. Mund, personal communication). The sum of harvest residues and root biomass was divided by the rotation length of 140 years and added to the average litter inputs. 
Table A1. Partitioning of the harvest residues and the root after harvest (excluding fine roots) to different inputs of the Yasso model. fwl: fine woody litter, cwl_small, coarse woody litter with a diameter diameter 6-20 cm, coarse woody litter with a diameter $20-60 \mathrm{~cm}$. Proportion of $\mathrm{fwl} / \mathrm{cwl}$ of roots is based on Kummetz (1996), proportion of cwl_small/cwl_large of roots is a reasonable guess according proportion coarse roots/stump. Other studies of root biomass do not distinguish different coarse roots with a diameter greater $2 \mathrm{~mm}$ (e.g. Drexhage and Gruber, 1998; Le Goff and Ottorini, 2001).

\begin{tabular}{lll}
\hline & Harvest residues & Root \\
\hline fwl & $25 \%$ & $21 \%$ \\
cwl_small & $67 \%$ & $55 \%$ \\
cwl_large & $8 \%$ & $24 \%$ \\
\hline
\end{tabular}

\section{Appendix B}

\section{Parameterization of the Yasso model}

Following tables list the standard parameters that have been applied to the Yasso Model for simulation experiments.

Climatic parameters (standard climate).

\begin{tabular}{lll}
\hline mat0 & $3.3^{\circ} \mathrm{C}$ & $\begin{array}{l}\text { standard mean annual temper- } \\
\text { ature }\end{array}$ \\
drought0 & $-32 \mathrm{~mm}$ & $\begin{array}{l}\text { standard precipitation - } \\
\text { potential evapotranspiration } \\
\text { from may to september } \\
\text { effect of mean annual temper- } \\
\text { ature } \\
\text { betfect of drought }\end{array}$ \\
\hline
\end{tabular}

Decomposition rates (k) and mass proportions of decay use to form more recalcitrant components $(\mathrm{p})$.

\begin{tabular}{llll}
\hline Compartment & $\mathrm{k}[1 / \mathrm{yr}]$ & $\mathrm{p}[1]$ & \\
\hline ext & 0.48 & 0.2 & conifers \\
ext_b & 0.82 & 0.2 & deciduous \\
cel & 0.30 & 0.2 & \\
lig & 0.22 & 0.2 & \\
hum1 & 0.012 & 0.2 & \\
hum2 & 0.0012 & 0 & \\
\hline
\end{tabular}

Standard relative sensitivity of slow pool decay rates to differences in temperature and drought.

$\begin{array}{ll}\mathrm{s} 1 \text { (hum1) } & 0.60 \\ \mathrm{~s} 2(\text { hum2) } & 0.36\end{array}$

Microbial invasion rates with standard climate.

\begin{tabular}{ll}
\hline compartment & $\mathrm{a}[1 / \mathrm{yr}]$ \\
\hline fwl & 0.540 \\
cwl_small & 0.077 \\
cwl_large & 0.030 \\
\hline
\end{tabular}

Chemical composition of litter, used in the equilibrium experiment (Pinus sylvestris).

\begin{tabular}{llll}
\hline compartment & ext & cel & lig \\
\hline nwl & 0.27 & 0.51 & 0.22 \\
fwl & 0.03 & 0.66 & 0.31 \\
cwl & 0.01 & 0.69 & 0.30 \\
\hline
\end{tabular}

Chemical composition of litter, used in the Leinefelde application (broadleaved).

\begin{tabular}{llll}
\hline compartment & ext & cel & lig \\
\hline nwl & 0.38 & 0.36 & 0.26 \\
fwl & 0.03 & 0.65 & 0.32 \\
cwl & 0.01 & 0.77 & 0.22 \\
\hline
\end{tabular}

Acknowledgements. The authors thank their participants of the international workshop on "Development of Models and Forest Soil Surveys for Monitoring of Soil Carbon" for fruitful discussions. Further we want to thank J. Leifeld, Z. Cai, and one anonymous reviewer for valuable comments that helped to improve the manuscript.

Edited by: Z. Cai

\section{References}

Ågren, G. I.: Temperature dependence of old soil organic matter, Ambio, 29, 55-55, 2000.

Ågren, G. I., Hyvönen, R., and Nilsson, T.: Are Swedish forest soils sinks or sources for $\mathrm{CO} 2$ - model analyses based on forest inventory data, Biogeochemistry, in press (online first), doi:10.1007/s10533-006-9064-0, 2007.

Baritz, R., De Neve, S., Brancikova, G., Gronlund, A., Leifeld, J., Katzensteiner, K., Koch, H. J., Palliere, C., Romanya, J., and Schaminee, J.: Task Group 5 - Land Use Practices and Soil Organic Matter, in: Reports of the Technical Working Groups established under the Thematic Strategy for Soil Protection. Volume 2 Soil Organic Matter Decline, edited by: Van-Camp, L., Bujarrabal, B., Gentile, A. R., Jones, R. J. A., Montanarella, L., Olazabal, C., and Selvaradjou, S.-K., Office for Official Publications of the European Communities, Luxembourg, 2004.

Berg, B., De Santo, A. V., Rutigliano, F. A., Fierro, A., and Ekbohm, G.: Limit values for plant litter decomposing in two contrasting soils - influence of litter elemental composition, Acta Oecologica-International J. Ecology, 24, 295-302, 2003.

Berg, B., Ekbohm, G., Johansson, M. B., McClaugherty, C., Rutigliano, F., and DeSanto, A. V.: Maximum decomposition 
limits of forest litter types: A synthesis, Canadian Journal of Botany-Revue Canadienne De Botanique, 74, 659-672, 1996.

Berg, B. and McClaugherty, C.: Plant Litter Decomposition, Humus Formation, Carbon Sequestration, Springer, Heidelberg, 2003.

Berger, T. W., Neubauer, C., and Glatzel, G.: Factors controlling soil carbon and nitrogen stores in pure stands of Norway spruce (Picea abies) and mixed species stands in Austria, For. Ecol. Manage., 159, 3-14, 2002.

Caspersen, J. P., Pacala, S. W., Jenkins, J. C., Hurtt, G. C., Moorcroft, P. R., and Birdsey, R. A.: Contributions of land-use history to carbon accumulation in US forests, Science, 290, 1148-1151, 2000.

Chertov, O. G., Komarov, A. S., Nadporozhskaya, M., Bykhovets, S. S., and Zudin, S. L.: ROMUL - a model of forest soil organic matter dynamics as a substantial tool for forest ecosystem modeling, Ecological Modelling, 138, 289-308, 2001.

Couteaux, M. M., Berg, B., and Rovira, P.: Near infrared reflectance spectroscopy for determination of organic matter fractions including microbial biomass in coniferous forest soils, Soil Biol. Biochemistry, 35, 1587-1600, 2003.

Couteaux, M. M., Bottner, P., and Berg, B.: Litter decomposition, climate and litter quality, Trends in Ecology \& Evolution, 10, 63-66, 1995.

Davidson, E. A. and Janssens, I. A.: Temperature sensitivity of soil carbon decomposition and feedbacks to climate change, Nature, 440, 165-173, 2006.

Dittmar, O., Knapp, E., and Lembcke, G.: DDR Buchenertragstafel 1983, IFE-Berichte aus Forschung und Entwicklung, 4, 1-59, 1986.

Drexhage, M. and Gruber, F.: Architecture of the skeletal root system of 40-year-old Picea abies on strongly acidified soils in the Harz Mountains (Germany), Canadian Journal of Forest Research-Revue Canadienne De Recherche Forestiere, 28, 1322, 1998.

Dupouey, J. L., Dambrine, E., Laffite, J. D., and Moares, C.: Irreversible impact of past land use on forest soils and biodiversity, Ecology, 83, 2978-2984, 2002.

Falloon, P., Smith, P., Coleman, K., and Marshall, S.: Estimating the size of the inert organic matter pool from total soil organic carbon content for use in the Rothamsted carbon model, Soil Biol. Biochemistry, 30, 1207-1211, 1998.

Fontaine, S. and Barot, S.: Size and functional diversity of microbe populations control plant persistence and long-term soil carbon accumulation, Ecology Lett., 8, 1075-1087, 2005.

Foster, D., Swanson, F., Aber, J., Burke, I., Brokaw, N., Tilman, D., and Knapp, A.: The importance of land-use legacies to ecology and conservation, Bioscience, 53, 77-88, 2003.

Goodale, C. L. and Aber, J. D.: The long-term effects of land-use history on nitrogen cycling in northern hardwood forests, Ecol. Applications, 11, 253-267, 2001.

Grandy, A. S. and Robertson, G. P.: Aggregation and organic matter protection following tillage of a previously uncultivated soil, Soil Sci. Soc. Am. J., 70, 1398-1406, 2006.

Harmon, M. E., Bible, K., Ryan, M. G., Shaw, D. C., Chen, H., Klopatek, J., and Li, X.: Production, respiration, and overall carbon balance in an old-growth Pseudotsuga-tsuga forest ecosystem, Ecosystems, 7, 498-512, 2004.

Hedges, J. I., Keil, R. G., and Benner, R.: What happens to terrestrial organic matter in the ocean?, Organic Geochemistry, 27,
195-212, 1997.

Howard, P. J. A. and Howard, D. M.: Microbial decomposition of tree and shrub leaf litter. 1. Weight loss and chemical composition of decomposing litter., Oikos, 25, 311-352, 1974.

Janssens, I. A., Lankreijer, H., Matteucci, G., Kowalski, A. S., Buchmann, N., Epron, D., Pilegaard, K., Kutsch, W., Longdoz, B., Grunwald, T., Montagnani, L., Dore, S., Rebmann, C., Moors, E. J., Grelle, A., Rannik, U., Morgenstern, K., Oltchev, S., Clement, R., Gudmundsson, J., Minerbi, S., Berbigier, P., Ibrom, A., Moncrieff, J., Aubinet, M., Bernhofer, C., Jensen, N. O., Vesala, T., Granier, A., Schulze, E.-D., Lindroth, A., Dolman, A. J., Jarvis, P. G., Ceulemans, R., and Valentini, R.: Productivity overshadows temperature in determining soil and ecosystem respiration across European forests, Global Change Biol., 7, 269278, 2001.

Jansson, P.-E. and Karlberg, L.: Coupled heat and mass transfer model for soil-plant-atmosphere systems, Royal Institute of Technolgy, Dept of Civl and Environmental Engineering, Stockholm, 2004.

Jenkinson, D. S.: The Turnover of Organic-Carbon and Nitrogen in Soil, Philosophical Transactions of the Royal Society of London Series B-Biological Sciences, 329, 361-368, 1990.

Kaipainen, T., Liski, J., Pussinen, A., and Karjalainen, T.: Managing carbon sinks by changing rotation length in European forests, Environ. Sci. Policy, 7, 205-219, 2004.

Koerner, W., Dambrine, E., Dupouey, J. L., and Benoit, M.: delta $\mathrm{N}-15$ of forest soil and understorey vegetation reflect the former agricultural land use, Oecologia, 121, 421-425, 1999.

Koerner, W., Dupouey, J. L., Dambrine, E., and Benoit, M.: Influence of past land use on the vegetation and soils of present day forest in the Vosges mountains, France, J. Ecology, 85, 351-358, 1997.

Kummetz, E.: Die Wurzelentwicklung der Fichte (Picea abies [L.] Karst.). Universität Bayreuth, Bayreuth, 1996.

Le Goff, N. and Ottorini, J. M.: Root biomass and biomass increment in a beech (Fagus sylvatica L.) stand in North-East France, Ann. For. Sci., 58, 1-13, 2001.

Lindner, M., Lucht, W., Bouriaud, O., Green, T., and Janssens, I. A.: Specific Study on Forest Greenhouse Gas Budget, Concerted Action CarboEurope-GHG, 2004.

Liski, J., Lehtonen, A., Palosuo, T., Peltoniemi, M., Eggers, T., Muukkonen, P., and Makipaa, R.: Carbon accumulation in Finland's forests 1922-2004 - an estimate obtained by combination of forest inventory data with modelling of biomass, litter and soil, Ann. For. Sci., 63, 687-697, 2006.

Liski, J., Palosuo, T., Peltoniemi, M., and Sievanen, R.: Carbon and decomposition model Yasso for forest soils, Ecological Modelling, 189, 168-182, 2005.

Liski, J., Perruchoud, D., and Karjalainen, T.: Increasing carbon stocks in the forest soils of western Europe, Forest Ecology and Management, 169, 159-175, 2002.

Liski, J. and Westman, C. J.: Carbon storage in forest soil of Finland .2. Size and regional patterns, Biogeochemistry, 36, 261-274, 1997.

Martel, Y. A. and Paul, E. A.: Use of Radiocarbon Dating of Organic-Matter in Study of Soil Genesis, Soil Sci. Soc. Am. J., 38, 501-506, 1974.

Mikutta, R., Kleber, M., Torn, M. S., and Jahn, R.: Stabilization of soil organic matter: Association with minerals or chemical 
recalcitrance?, Biogeochemistry, 77, 25-56, 2006.

Mund, M.: Carbon pools European beech forests (Fagus sylvatica) under different silvicultural management, University Göttingen, Göttingen, 2004.

Mund, M. and Schulze, E.-D.: Silviculture and its interactions with biodiversity and the carbon balance of forest soils, in: Forest diversity and function: temperate and boreal Systems, edited by: Scherer-Lorenzen, M., Körner, C., and Schulze, E.-D., Springer, Berlin Heildelberg New York, 2005.

Nabuurs, G. J. and Schelhaas, M. J.: Carbon profiles of forests across Europe, an application of co2fix., Ecological Indicators, 1, 213-223, 2002.

Palosuo, T., Liski, J., Trofymow, J. A., and Titus, B. D.: Litter decomposition affected by climate and litter quality - Testing the Yasso model with litterbag data from the Canadian intersite decomposition experiment, Ecological Modelling, 189, 183-198, 2005.

Parker, J. L., Fernandez, I. J., Rustad, L. E., and Norton, S. A.: Effects of nitrogen enrichment, wildfire, and harvesting on forestsoil carbon and nitrogen, Soil Sci. Soc. Am. J., 65, 1248-1255, 2001.

Parton, W. J., Stewart, J. W. B., and Cole, C. V.: Dynamics of C, $\mathrm{N}, \mathrm{P}$ and $\mathrm{S}$ in Grassland Soils - a Model, Biogeochemistry, 5, 109-131, 1988.

Peltoniemi, M., Makipaa, R., Liski, J., and Tamminen, P.: Changes in soil carbon with stand age - an evaluation of a modelling method with empirical data, Global Change Biology, 10, 20782091, 2004.

Perruchoud, D., Walthert, L., Zimmermann, S., and Luscher, P.: Contemporary carbon stocks of mineral forest soils in the Swiss Alps, Biogeochemistry, 50, 111-136, 2000.

Polyakov, V. and Lal, R.: Modeling soil organic matter dynamics as affected by soil water erosion, Environ. Int., 30, 547-556, 2004.

Rothe, A., Kreutzer, K., and Kuchenhoff, H.: Influence of tree species composition on soil and soil solution properties in two mixed spruce-beech stands with contrasting history in Southern Germany, Plant and Soil, 240, 47-56, 2002.

Rumpel, C., Kogel-Knabner, I., and Bruhn, F.: Vertical distribution, age, and chemical composition of organic, carbon in two forest soils of different pedogenesis, Organic Geochemistry, 33, 11311142, 2002.

Schröter, D., Acosta-Michlik, L., Arnell, A. W., Araújo, M. B., Badeck, F., Bakker, M., Bondeau, A., Bugmann, H., Carter, T., de la Vega-Leinert, A. C., Erhard, M., Espiñeira, G. Z., Ewert, F., Fritsch, U., Friedlingstein, P., Glendining, M., Gracia, C. A., Hickler, T., House, J., Hulme, M., Kankaanpää, S., Klein, R. J. T., Krukenberg, B., Lavorel, S., Leemans, R., Lindner, M., Liski, J., Metzger, M. J., Meyer, J., Mitchell, T., Mohren, F., Morales, P., Moreno, J. M., Reginster, I., Reidsma, P., Rounsevell, M., Pla, E., Pluimers, J., Prentice, I. C., Pussinen, A., Sánchez, A., Sabaté, S., Sitch, S., Smith, B., Smith, J., Smith, P., Sykes, M. T., Thonicke, K., Thuiller, W., Tuck, G., van der Werf, G., Vayreda, J., Wattenbach, M., Wilson, D. W., Woodward, F. I., Zaehle, S., Zierl, B., Zudin, S., and Cramer, W.: ATEAM Final report 2004, Potsdam Institute for Climate Impact Research, Potsdam, Germany, 2004.
Smith, J., Smith, P., Wattenbach, M., Zaehle, S., Hiederer, R., Jones, R. J. A., Montanarella, L., Rounsevell, M. D. A., Reginster, I., and Ewert, F.: Projected changes in mineral soil carbon of European croplands and grasslands, 1990-2080, Global Change Biology, 11, 2141-2152, 2005.

Smith, P., Smith, J. U., Powlson, D. S., McGill, W. B., Arah, J. R. M., Chertov, O. G., Coleman, K., Franko, U., Frolking, S., Jenkinson, D. S., Jensen, L. S., Kelly, R. H., Klein-Gunnewiek, H., Komarov, A. S., Li, C., Molina, J. A. E., Mueller, T., Parton, W. J., Thornley, J. H. M., and Whitmore, A. P.: A comparison of the performance of nine soil organic matter models using datasets from seven long-term experiments, Geoderma, 81, 153225, 1997.

Thornton, P.: Description of a numerical simulation model for predicting the dynamics of energy, water, carbon, and nitrogen in a terrestrial ecosystem, 1998.

Thornton, P. E., Law, B. E., Gholz, H. L., Clark, K. L., Falge, E., Ellsworth, D. S., Golstein, A. H., Monson, R. K., Hollinger, D., Falk, M., Chen, J., and Sparks, J. P.: Modeling and measuring the effects of disturbance history and climate on carbon and water budgets in evergreen needleleaf forests, Agricul. For. Meteorol., 113, 185-222, 2002.

von Lützow, M., Kogel-Knabner, I., Ekschmitt, K., Matzner, E., Guggenberger, G., Marschner, B., and Flessa, H.: Stabilization of organic matter in temperate soils: mechanisms and their relevance under different soil conditions - a review, European J. Soil Sci., 57, 426-445, 2006.

Wall, A. and Hytonen, J.: Soil fertility of afforested arable land compared to continuously forested sites, Plant and Soil, 275 , 247-260, 2005.

Wardle, D. A., Hornberg, G., Zackrisson, O., Kalela-Brundin, M., and Coomes, D. A.: Long-term effects of wildfire on ecosystem properties across an island area gradient, Science, 300, 972-975, 2003.

Wardle, D. A., Zackrisson, O., Hornberg, G., and Gallet, C.: The influence of island area on ecosystem properties, Science, 277, 1296-1299, 1997.

Weiss, P., Schieler, K., Schadauer, K., Radunsky, K., and Englisch, M.: Die Kohlenstoffbilanz des österreichischen Waldes und Betrachtungen zum Kyoto-Protokoll (The carbon balance of the Austrian forest and considerations in view of the Kyotoprotocol), Umweltbundesamt, Vienna, Austria, 2000.

Wirth, C., Schulze, E.-D., Schwalbe, G., Tomczyk, S., Weber, G., and Weller, E.: Dynamik der Kohlenstoffvorräte in den Wäldern Thüringens- Abschlussbericht zur 1, Phase des BMBF-Projektes "Modelluntersuchung zu Umsetzung des Kyoto-Protokolls", Thüringer Landesanstalt für Jagd, Wald und Fischerei, Jena Gotha, 2004.

Wutzler, T., Köstner, B., and Bernhofer, C.: Spatially Explicit Assessment of Carbon Stocks of a Managed Forest Area in Eastern Germany, J. European For. Res., online first, doi:10.1007/s10342-006-0155-1, 2006.

Zimmermann, M., Leifeld, J., and Fuhrer, J.: Quantifying soil organic carbon fractions by infrared-spectroscopy, Soil Biology and Biochemistry, 39, 224-231, 2007. 